\title{
EL DIOS MAYA DE LA LLUVIA EN EL CÓDICE DE DRESDE Y LOS HUESOS ESGRAFIADOS DE LA TUMBA DEL TEMPLO I DE TIKAL
}

\section{Por Marta Foncerrada de Molina}

El tema del presente ensayo es apuntar unas cuentas reflexiones sobre la intrigante relación estilística y posiblemente temática que existe entre las representaciones del dios de la lluvia, que en el Códice Dresde aparece en una barca, y los estupendos dibujos esgrafiados en los huesos encontrados en 1962 en la tumba del Templo I de Tikal; en los diseños de dos de estos huesos se observan varias representaciones que muestran la dinámica figura del mismo dios que, en una barca o sumergido en el agua, se entrega a las tareas de pescador.

Las recientes investigaciones sobre la secuencia cultural de Tikal sitúan el contenido del entierro 116 , del que formaron parte los huesos esgrafiados, dentro del Clásico Tardío Maya (ca. 600-900 d.C.). ${ }^{1}$

La situación en el tiempo, así como la procedencia del Códice de Dres$d e$ no ha podido aún determinarse. El manuscrito maya posee elementos que lo relacionan con el estilo artístico y la cultura del periodo Clásico Maya, y otros que parecen reflejar la influencia mexicana que durante el Postclásico recibieron los mayas de Yucatán y los de las regiones Quiché y Cakchiquel en Guatemala.

Las "páginas" del Códice de Dresde que muestran al dios de la lluvia remando y que corresponden al reverso del manuscrito son las siguientes:

$$
\begin{array}{cl}
\text { "pág." } & 65 b-\text { ler. cuadro } \\
" & 29 c-\text { ler. cuadro } \\
" & 36 b-2 o . \text { cuadro } \\
" & 40 a-\text { ler. cuadro } \\
" & 40 c-\text { ler. cuadro } \\
\text { " } & 43 c-\text { ocupa toda la } \\
\text { sección. }
\end{array}
$$

(44 paginación moderna)

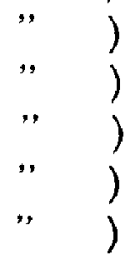

Las "páginas" 29, 36, 40 y 43 pertenecen a las secciones augúricas del Códice y están presididas pictóricamente, casi exclusivamente, por el dios de la lluvia o dios "B", como lo denominó Schellhas en el estudio que

1 Coe, 1965. $†$ p. 41. 
publicó en 1904, sobre las representaciones de los dioses en los códices mayas.

Las características constantes de las seis representaciones que en el Códice de Dresde muestran al dios de la lluvia en una barca y las del mismo dios en los huesos de Tikal, pueden resumirse en la siguiente tabla:

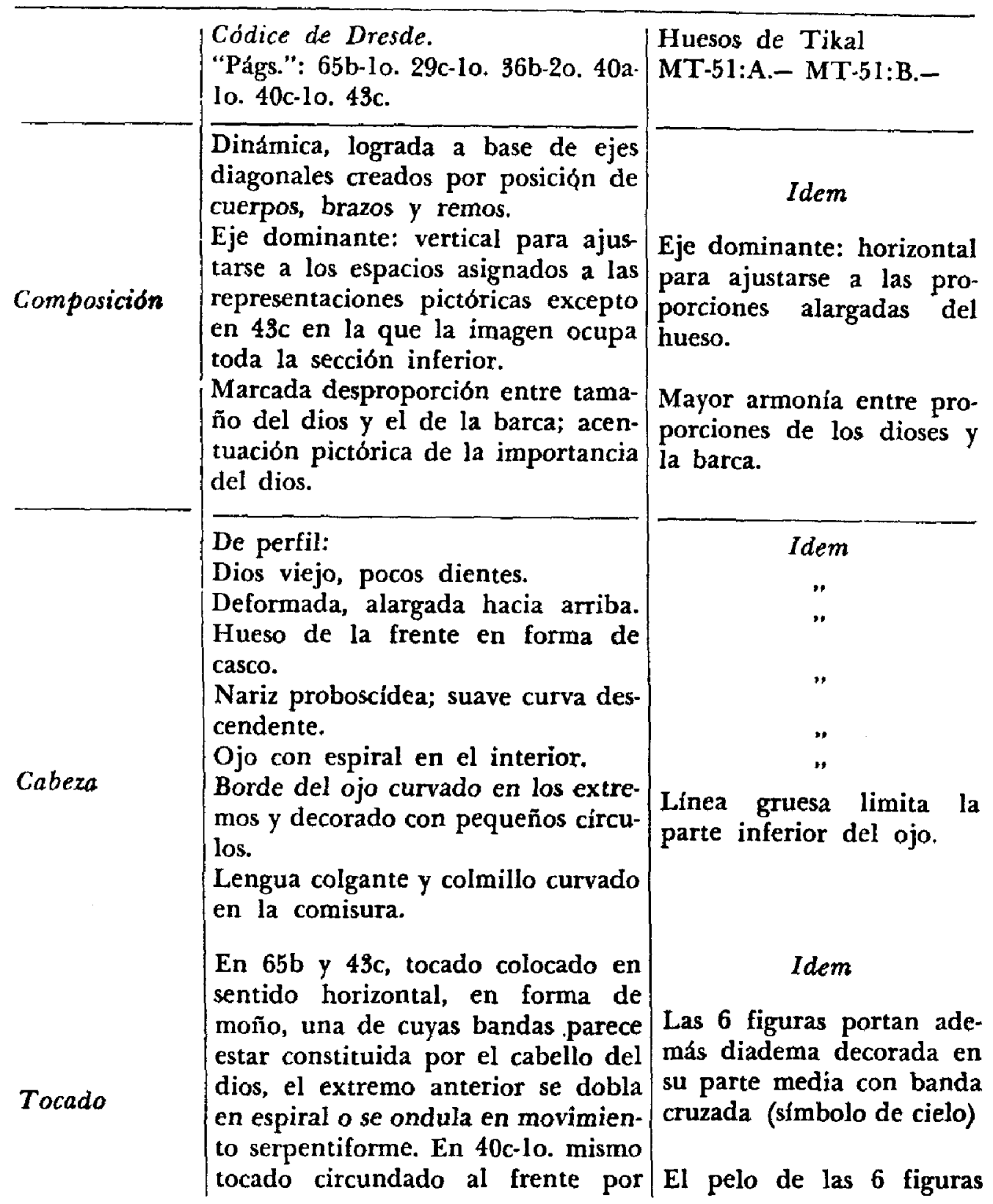




\begin{tabular}{|c|c|c|}
\hline & $\begin{array}{l}\text { pequeños círculos (simbolo de las } \\
\text { estrellas) Figs. 29c-lo. 36b-2o. y } \\
\text { 40a-lo. No llevan tocado. Pelo in- } \\
\text { dicado por lineas de puntos. }\end{array}$ & $\begin{array}{l}\text { está representado por finas } \\
\text { líneas paralelas. }\end{array}$ \\
\hline Cuerpo & $\begin{array}{l}\text { Antropomorfo. } \\
\text { Dios sentado o hincado en la barca } \\
\text { con el cuerpo totalmente visible. } \\
\text { De perfil } \\
\text { En } 65 \text { b-lo, el torso y los brazos es- } \\
\text { tán en posición frontal. Pierna de- } \\
\text { recha flexionada, de perfil y la } \\
\text { izquierda en escorzo. } \\
\text { Dibujo compacto excepto en } 65 \mathrm{~b}-10 .\end{array}$ & $\begin{array}{l}\text { Idem } \\
\text { Parte del cuerpo no es vi- } \\
\text { sible. } \\
\text { MT-51:A- En la barca: } \\
\text { figura de pie de perfil otra } \\
\text { de frente, la sumergida en } \\
\text { el agua de frente; brazos } \\
\text { extendidos. } \\
\text { MT-51:B.- Figs. de pie en } \\
\text { la barca y la sumergida en } \\
\text { el agua de perfil. } \\
\text { La otra en la barca, de } \\
\text { frente. } \\
\text { Espalda, brazos y piernas } \\
\text { decorados. }\end{array}$ \\
\hline Vestuario & $\begin{array}{l}\text { Taparrabo decorado con círculos y } \\
\text { barras. } \\
\text { Lazo sencillo cae por la cadera. } \\
\text { Puños y cubretobillos. }\end{array}$ & $\begin{array}{l}\text { Idem } \\
\text { Elaborado lazo cae por la } \\
\text { cadera. } \\
\text { Puños. }\end{array}$ \\
\hline Adorno & $\begin{array}{l}\text { Collar de cuentas redondas. } \\
\text { Orejeras compuestas por varios ele- } \\
\text { mentos. Remate serpentino. } \\
\text { En } 65 \text { b-lo. la orejera tiene forma } \\
\text { de hueso, abierto en forma de gan- } \\
\text { cho en su extremo inferior. Este } \\
\text { tipo de orejera es habitual en el } \\
\text { dios de la muerte ("A"). } \\
\text { Nasion en forma de virgula Fig. } \\
40 \text { c-lo. Nasión en forma de vírgula } \\
\text { con remate de cuenta redonda y } \\
2 \text { tubulares. }\end{array}$ & $\begin{array}{l}\text { Idem en las figuras que } \\
\text { apoyan la barba en el bor- } \\
\text { de superior de la barca. } \\
\text { Idem } \\
\text { Nasión compuesta por una } \\
\text { cuenta redonda y otra tu- } \\
\text { bular. }\end{array}$ \\
\hline
\end{tabular}

En la esquina superior de cada uno de los huesos aparece una inscripción jeroglffica compuesta por seis signos de los cuales el segundo parece ser una variante de cabeza del jeroglífico nominal del dios de la lluvia mientras que el sexto es el glifo emblema de Tikal. Los cuatro restantes no han sido interpretados aún, éstos parecen referirse a adivinaciones 
calendáricas más que a eventos reales. ${ }^{2}$ Esta característica muestra que el paralelismo entre los dibujos esgrafiados de Tikal y el Códice de Dresde es, además de estilístico e iconográfico, posiblemente temático.

Para los fines del presente ensayo considero que deben quedar apuntadas dos observaciones importantes respecto al significado del texto jeroglifico que acompaña a las seis representaciones del dios de la lluvia en el Códice de Dresde, analizados en la tabla comparativa. Estas observaciones surgen como resultantes de la crítica interna del manuscrito maya.

La primera es la que muestra el dios de la lluvia en 43c y en 65bl como deidad auspiciadora de buenas cosechas, ejerciendo para bienestar del hombre, sus poderes benéficos. Estas hipótesis son el resultado del trabajo de dos investigadores que se han ocupado por interpretar el posible significado simbólico contenido en dos de las secuencias pictográficas del Códice entre las que se encuentran la representación del dios de la lluvia conduciendo una barca. Eric Thompson en 1950 (Apéndice 1) se refirió a las secciones $42 \mathrm{c}$ a $45 \mathrm{c}$, y Thomas Barthel en 1953 (apéndice 2), analizó la secuencia 65b a 69b. En ambos trabajos los autores consideran que el dios, tanto en $43 \mathrm{c}$ como en $65 \mathrm{bl}$, aparece como deidad benévola.

La segunda se refiere a las variantes que Zimmermann encontró en el dibujo del jeroglifico nominal del dios de la lluvia en varias de las "páginas" en que está dividido el Códice. ${ }^{3}$

Zimmermann agrupó en una misma categoría los dibujos de los jeroglíficos nominales del dios de la lluvia que se encuentran en las "páginas" 29,26 y 40 , en otra, a los de las "páginas" 43 y en una más, a los de la "página" 65. La distinción que el autor hace entre unos y otros jeroglificos es importante porque, a mi juicio, coincide con las mismas variantes estilísticas en el dibujo de las figuras del dios de la lluvia en las "páginas" que Zimmermann agrupa como distintas entre sí. Estas diferencias estilísticas son, en ambos casos, poco acentuadas, pero suficientes para sugerir la intervención de varios artistas en la ejecución del Códice.

El artista que ejecutó las representaciones pictóricas de las páginas 29 a 31 y 36 a 41 , dentro de las que están incluidas cuatro de los dioses tratados en este trabajo, poseen un carácter estilistico homogéneo. El movimiento de la línea es mesurado, está contenido dentro de la figura y jamás rebasa los límites del espacio que le asigna la sección que le

2 Satterthwaite, 1963. $†$ p. 19.

3 Zimmermann, 1956. † Tabla 6. 
corresponde dentro de las subdivisiones requeridas por la secuencia del calendario ritual.

En el grupo mencionado en el párrafo anterior merece una mención especial la sección $36 \mathrm{~b} 2$ por su calidad estética. En los tres cuadretes restantes los dioses navegan solos, en $36 \mathrm{~b} 2$ el dios de la lluvia va acompañado por la figura naturalista del joven dios del maiz, sentado a la manera oriental en la proa de la nave; el jeroglífico nominal de este dios aparece en primer término en el texto superior correspondiente. El artista logró crear en esta miniatura una composición perfectamente equilibrada en la que, con fina sensibilidad, estableció sutiles relaciones de contraste entre las proporciones de ambas figuras, más pequeña la del dios del maíz que la del dios narigudo y en las diferencias en el diseño del rostro humanizado y naturalista del joven dios y las exageradas facciones del viejo y desdentado dios de la lluvia.

El dibujo en las páginas 65b 1 y 43c es menos delicado que el analizado anteriormente; el trazo es más amplio y esquemático y se evitó, en el diseño, la profusión de formas circulares que caracterizan a los 4 dioses ya mencionados. En 65b 1 y 43 c se observa una cierta dureza en la expresión del rostro de los dioses que en $43 \mathrm{c}$ adquiere un carácter francamente geometrizante y justifica el que se le considere artísticamente distinto al de 65b 1.

El tipo de impacto visual que producen ambas imágenes obedece también a su tamaño, mayor que el de las otras representaciones: 65b I pertenece a una "página" del Códice dividida horizontalmente en sólo dos secciones que contienen, cada una, tres deidades; la representación del dios en 43c ocupa toda la sección inferior de la página que está dividida horizontalmente en tres partes, mientras que a las páginas 29c, 36 y 40 a corresponden 9 deidades, tres en cada una de las divisiones horizontales.

Las diferencias perceptibles en el trazo de los jeroglificos, en el dibujo de las imágenes y en las distintas formas en que fueron divididas las "páginas" del Códice parece indicar la presencia de diferentes escribas. Esta hipótesis no ayuda a esclarecer el problema que se refiere al proceso temporal por el que atravesó la ejecución del Códice, lo que permitiría una mayor comprensión de la trayectoria histórica del pensamiento religioso maya, ya que la intervención de varios artistas en el Códice bien pudo haber sido simultánea $\mathrm{y}$, por lo tanto, coetánea.

Si se acepta al Códice de Dresde como la obra completa de un solo periodo histórico podría decirse que los dibujantes mayas, posiblemente sacerdotes además de artistas, no estuvieron sujetos a los estrictos cámones 
artísticos que se le impusieron al arte escultórico monumental en las diferentes provincias estilísticas en que está dividida el área maya, sino que éstos tuvieron mayor libertad para ejercer su arte y organizar aś en variadas formas las diversas secciones que componen el manuscrito religioso:

Volviendo a la relación artística entre los dibujos esgrafiados de los huesos de Tikal y los dioses navegantes del Códice de Dresde, encuentro que una de las diferencias importantes que distinguen a unas imágenes de otras está en relación con el sentido que, a mi juicio, tiene la repre. sentación en sí; en el Códice éste parece estar circunscrito a la exclusiva presentación de la deidad dentro del marco de una secuencia calendárica de carácter augúrico o adivinatorio. Los dibujos de los huesos de Tikal se ocupan de la narración de un evento mítico, en el que el dios de la lluvia, desdoblado en tres, participa activamente en una animada escena acuática. La escena posee gran vitalidad por el realismo con que fueron ejecutadas las distintas actitudes de los dioses y por la dinámica relación que el artista logró establecer entre las imágenes mismas, tal que parece percibirse el diálogo que sostiene el dios remero con el que está sumergido en el agua.

La estrecha relación que existe entre cada una de las 3 figuras de los 2 huesos de Tikal se logró por un procedimiento de alta calidad artística. Las figuras están ligadas entre sí por una línea imaginaria ondulante que inicia su suave movimiento ascendente en el pescado que sostiene el dios agachado sobre la proa de la embarcación, sube hasta el remate del penacho del dios que rema de pie y desciende por el que, inmerso en el agua hasta medio cuerpo, pesca, y va a desvanecerse en las pequeñas formas ondulantes que representan el agua. El mismo movimiento puede seguirse en sentido inverso, de modo que forma una elegante cadena de amplios eslabones.

Las imágenes del dios en el Códice son estáticas, encerradas cada una en el cuadrete que le corresponde no tienen relación con las que las circundan $y$ pueden analizarse formalmente como unidades aisladas; éstas, por otra parte, sí presentan un patrón homogéneo de composición como se vio en la tabla comparativa.

El carácter presentativo del Códice y el narrativo de los huesos de Tikal se hace aún más patente cuando se observa la sección $36 \mathrm{~b} 20$. del primero en el que el viejo dios de la lluvia conduce en la misma barca al joven dios del maíz; aquí, las figuras están simplemente yuxtapuestas, no hay diálogo entre ellas, mientras que entre las figuras de los huesos de Tikal este diálogo está claramente indicado por la estruc- 
tura misma del diseño y se hace aún más abvio porque los dos dioses que, en cada caso, conversan entre si, fueron representados con la boca abierta.

La línea que perfila las figuras tanto en el Códice como en los dibujos esgrafiados de los huesos de Tikal es muy semejante: línea maya, fina y segura que se mueve fluidamente y que, sin titubeos, limita con precisión todos los elementos que entran en la composición. El espíritu barroco maya se revela en el juego armónico de líneas curvas que definen los accesorios ornamentales y le imprimen variado movimiento a las figuras acentuando el carácter dinámico del diseño. Esta línea es aún más delicada y fina en los dibujos de los huesos de Tikal como puede comprobarse si se observa cómo están tratadas las manos; éstas corresponden a la misma sensibilidad que creó los relieves esculpidos dẹ larte monumental maya del periodo Clásico. En el Códice de Dresde el dibujo de las manos es con frecuencia torpe y un tanto burdo.

El contenido simbólico de las representaciones del dios de la lluvia, en ambos casos, parece referirse a los poderes del dios ligados con la fecundidad de la tierra. Son frecuentes en el arte maya las representaciones del dios de la lluvia que lo muestran asociado con plantas, frutas y pescados, lo que alude al poder de ubicuidad que el sentir religioso maya le atribuyó a esta deidad, la que consideró, sin duda, intimamente involucrada con la fecundidad no sólo de los campos sino también de las regiones acuáticas. Lo anterior indica el afán maya por invocar la presencia real del dios en el ámbito terrenal para que su acción benefactora no se restringiera únicamente al ejercicio de su dominio sọbre el sol, las nubes y el viento en la región celeste, sino que el despliegue de su poder divino en la tierra le diera impulso al proceso creativo de la naturaleza.

Linton Satterthwaite, distinguido antropólogo de la Universidad de Pennsylvania y especialista en cultura maya, al estudiar los dibujos esgrafiados de los huesos de Tikal, encontró semejanzas entre los glifos y las representaciones pictóricas de éstos y las secciones augúricas de los códices a los que considera más tardíos y alejados geográficamente de Tikal.

No es posible aún definir con suficiente exactitud las relaciones de semejanza que conectan entre sí ambas manifestaciones artísticas; sirva, al menos, el señalarla para apuntar una vez más la continuidad en el tiempo y en el espacio de los patrones simbólico-religiosos y artísticos de la cultura maya. 
APtendice 1. Según Eric Thompson la representación del dios "B" correspondiente a la sección 43c, lo muestra como deidad benévola; el autor reconstruye el texto jeroglífico como sigue: " $B$ " está orientado (??) hacia el Este. Muy bueno (para) la semilla del maiz. "Abundancia de maiz." 4 Esta imagen es parte de una serie que comprende las secciones $42 \mathrm{c}$ a $45 \mathrm{c}$, las que han sido interpretadas por el mismo autor en los siguientes términos: "Los almanaques adivinatorios en Dresde $42 c$ a $45 c$, están divididos en cuatro secciones de 65 días y posiblemente tienen conexión con ceremonias de fuego ya que las secciones empiezan, respectivamente, con los dias 4 Ahau, 4 Chicchán, 4 Oc y 4 Men, días que se consideran los 'gobernantes', en los que los quemadores dejan que el fuego corra; * cada división está asociada con un punto cardinal y contiene además el glifo del perro que, entre otros, es símbolo del fuego." 5

APENDiCE 2. Thomas Barthel realizó en 1953 un estudio sobre las secciones 65b a 69b del Códice de Dresde y concluyó que las trece representaciones pictóricas de la imagen del dios " $B$ " que en ellas aparecen se refieren a los lugares de estancia del dios en los 13 niveles en los que la mentalidad religiosa maya dividió la región celeste.

En el cuadro 65b-lo, el dios de la lluvia sentado en una barca, rema en el agua en la que nada un pez rayado. Según Barthel la explicación de esta representación se encuentra en la imagen del mundo mexicano que representaba a la tierra rodeada de agua; el dios aquí parece navegar en donde se cruza el horizonte, es decir, donde cielo y tierra se juntan, lo cual tiene conexión con los niveles celestes en cuanto que éstos indican las sucesivas estaciones del sol de acuerdo con su diario recorrido por el firmamento y que, en este caso, corresponden al de su ocaso, al cielo nocturno. El autor piensa que, tal vez, pueda interpretarse esta metáfora como una alusión a la región del Pánuco o "Panohuayan", lugar donde se cruza el agua que aparece en las leyendas de los caminantes mexicanos. El significado augúrico contenido en esta representación es el de "maíz tierno, muy bueno". 6

El autor explica el método que siguió para la interpretación de esta sección del Códice de Dresde en los siguientes términos: "La designación de los lugares del dios de la lluvia en Sec. 65 b a $69 \mathrm{~b}$ se trató de hacer de la manera siguiente: las metáforas esotéricas que aparecen en los himnos a los dioses según fueron recogidos por Sahagún se relacionaron con las representaciones pictóricas del Códice de Dresde. Del lado mexicano se trataba de una fuente nahua antigua, comentada y explicada por un texto azteca el que fue traducido por Seler. En el Códice maya, más o menos contemporáneo a la fuente nahua se elaboró una cadena de datos que pusieron en relación comprensible los datos de esta fuente con las 13 imágenes representadas

4 Thompson, 1960. + p. 273.

- Esto parece aludir a la quema de los campos aún practicada en Yucatán por los mayas modernos como método para preparar la tierra antes de la siembra.

5 Ibid. Fig. 61. †

6 Barthel, 1953. pp. 95 y 98. 
en la sección $65 \mathrm{~b}$ a $69 \mathrm{~b}$ del Códice maya y con los jeroglificos locativos y atributivos que acompañan a dichas imágenes." 7

Las conclusiones a que llega Barthel mediante el análisis de la estructura interna de los jeroglíficos en el texto del Códice y las relaciones que establece entre éstas y las representaciones pictóricas son un tanto confusas e imprecisas. El punto débil de la tesis de Barthel, es, a mi juicio, que a pesar de la especial mención que hace del peligro que entraña basar la interpretación del contenido simbólico de la región maya a la luz de la del Altiplano, fundamente sus argumentos precisamente en paralelismos ambiguos que conectan artificialmente el significado de las escenas representadas en el Códice de Dresde con los lugares míticos asignados al dios azteca de la lluvia, Tláloc, según éstos fueron descritos en los himnos a los dioses recogidos por Sahagún.

La relación de analogia que Barthel establece entre los lugares de estancia del dios de la lluvia azteca y el maya es incompleta porque está basada exclusivamente en fuentes de la cultura náhuatl; el autor no menciona en su estudio comparativo ningún documento escrito maya en el que pudieran encontrarse relaciones entre los dioses mayas de la lluvia y las imágenes en el Códice de Dresde o que las mostrara en un contexto similar al de los himnos aztecas a Tláloc.

Barthel basó la posibilidad de relación entre la sección $65 \mathrm{~b}$ a $69 \mathrm{~b}$ del Códice de Dresde y los textos nahuas en la supuesta contemporaneidad de ambas fuentes considerando el contenido simbólico religioso de los himnos a los dioses como un "ejemplo de la expansión de las ideas mayas en la tradición nahua tardia." 8 Esta afirmación de Barthel, que hubiera requerido una amplia explicación parece implicar que existió una corriente de influencia maya en el Altiplano que originó en las culturas de esta área la elaboración de un conjunto de ideas religiosas que fueron preservadas por los grupos del periodo postclásico y finalmente vertidas en los himnos a los dioses de la literatura azteca. Al llevar a sus últimas consecuencias la hipótesis del autor se pone de relieve que ésta no puede servir de base para una interpretación cientifica del significado religioso de las representaciones del dios de la lluvia en el Códice de Dresde porque, a pesar de la erudición con que el investigador alemán maneja el tema, el problema de la antigüedad y lugar de origen de este manuscrito sigue siendo aún una de las incógnitas que los estudios sobre cultura maya no han podido resolver. Por otra parte, no es posible demostrar la expansión de las ideas mayas en la tradición nảhua utilizando como prueba la descripción que las fuentes aztecas hacen de sus dioses y colgándole ésta a un documento pictórico maya cuyo texto jeroglífico se conoce sólo parcialmente.

\section{BIBLIOGRAFfa}

Barthel, Thomas S. "Regioneu des Regengothes." Reprinted from Ethnos. The Etnographical Museum of Sweden, Stockholm; núms. 1 y 2. 1953.

7 Ibid. p. 66.

8 lbid. p. 87. 
Codex Dresdensis. Akademie - Verlag. Berlin. 1962.

CoE, William R. "Tikal: Ten years of study of a Maya Ruin in the Lowlands of Guatemala." Expedition. Vol. 8 núm 1. Fall. University of Pennsylvania, Philadelphia. 1965.

DeCRerT, Helmut Von. "Maya Handschrift." Der Sächsischen Landesbibliothek Dresden. "Codex Dresdensis." Geschechte und Bibliographie. Akademie. Verlag. Berlin. 1962.

Förstemann, Ernst. "Commentary of the Maya Manuscript in the Royal Public Library of Dresden." Translated by Miss Selma Wesselhoeft and Miss A. M. Parker. Papers of the Peabody Museum of American Archaeology and Ethnology. Harvard University. Vol. Iv, núm. 2. Cambridge, Mass. 1906.

Garubay K., Angel Ma. "Veinte Himnos Sacros de los Nahuas." Fuentes Indige. nas de la Cultura Nahuatl. Informantes de Sahagún, 2. Instituto de Historia: Seminario de Cultura Nahuatl. UNAM. México. 1958.

LaNDA, Diego de. "Relación de las Cosas de Yucatán." 7a. edición. Introducción y notas de Héctor Pérez Martínez. México. 1938.

Landa, Diego de. "Relación de las Cosas de Yucatán." Edited with notes by Alfred M. Tozzer. Papers of the Peabody Museum of American Archaeology and Ethnology. Harvard University. Vol. xvIII. Cambridge, Mass. 1941.

SatTerthwarte, Linton. Note on Hieroglyphics on Bone from the Tomb below Temple I, Tikal. Expedition. Vol. 6 núm. 1. Fall. University of Pennsylvania, Philadelphia. 1963.

Schellhas, Paul. "Representations of Deities of the Maya Manuscripts." 2nd. ed. Translated by Selma Wesselhoeft and A. M. Parker. Papers of the Peabody Museum of American Archacology and Ethnology. Harvard University. Vol. Iv, núm. 1. Cambridge, Mass. 1904.

Thompson, J. Eric. "Maya Hieroglyphic Writing." University of Oklahoma Press: Norman. 1960.

TRIR, Audrey S. "The Splendid Tomb of Temple I at Tikal, Guatemala." Expedition. Vol. 6, núm. 1. Fall. University of Pennsylvania Philadelphia. 1963.

ZrmmermanN, Günter. "Die Hieroglyphen der Maya-Handschriften." Universität Hamburg. Abhand lungen aus dem Gebiet der Auslands Kunde. Hamburg. 1956.

Villacorta C., José A., y Carlos. Códices Mayas. Guatemala. 1930. 
DOI: http://dx.doi.org/10.22201/iie.18703062e.1967.36.838

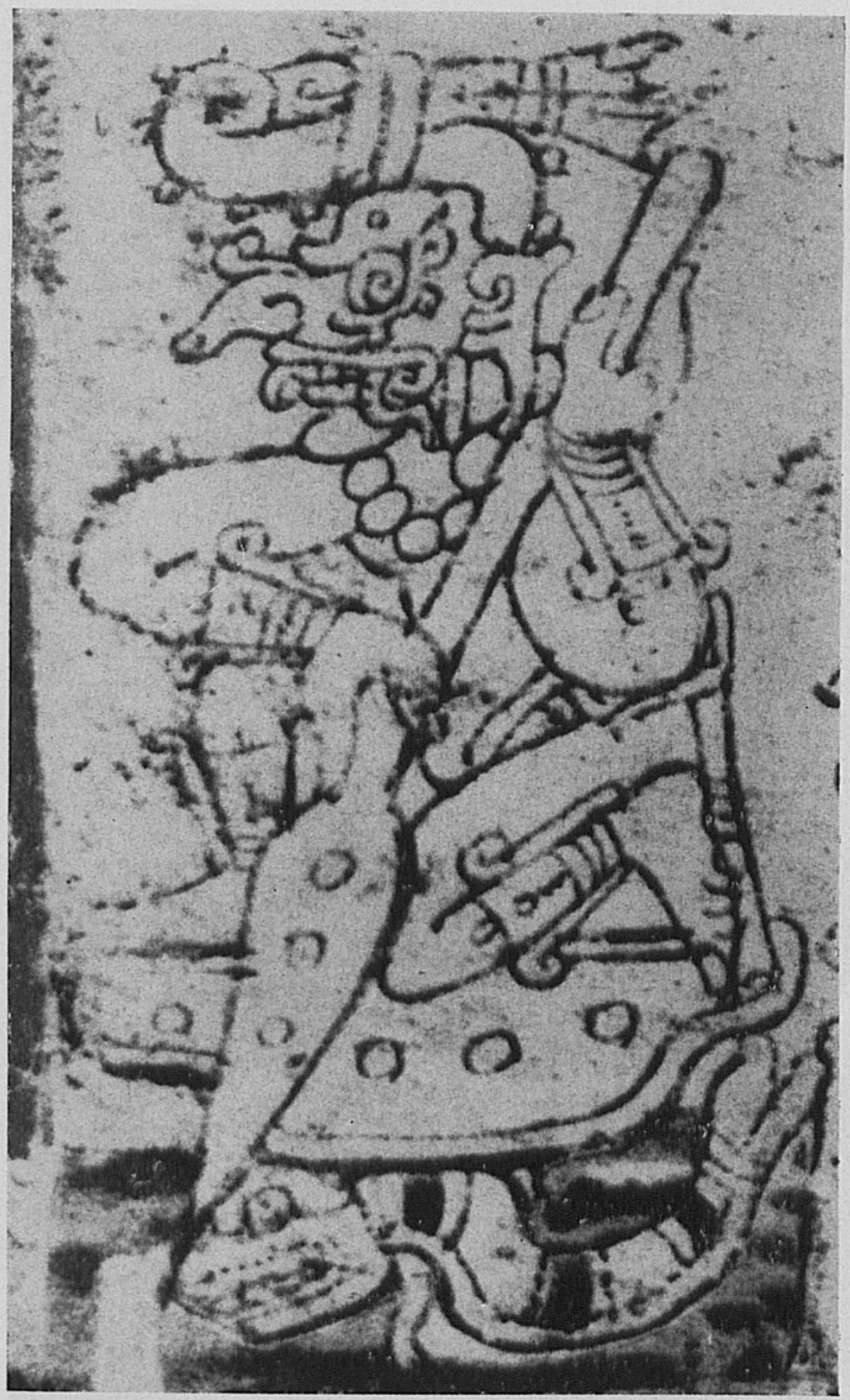

1. Dios de la lluvia. Códice de Dresde, p. 65 b-ler. cuadro. 


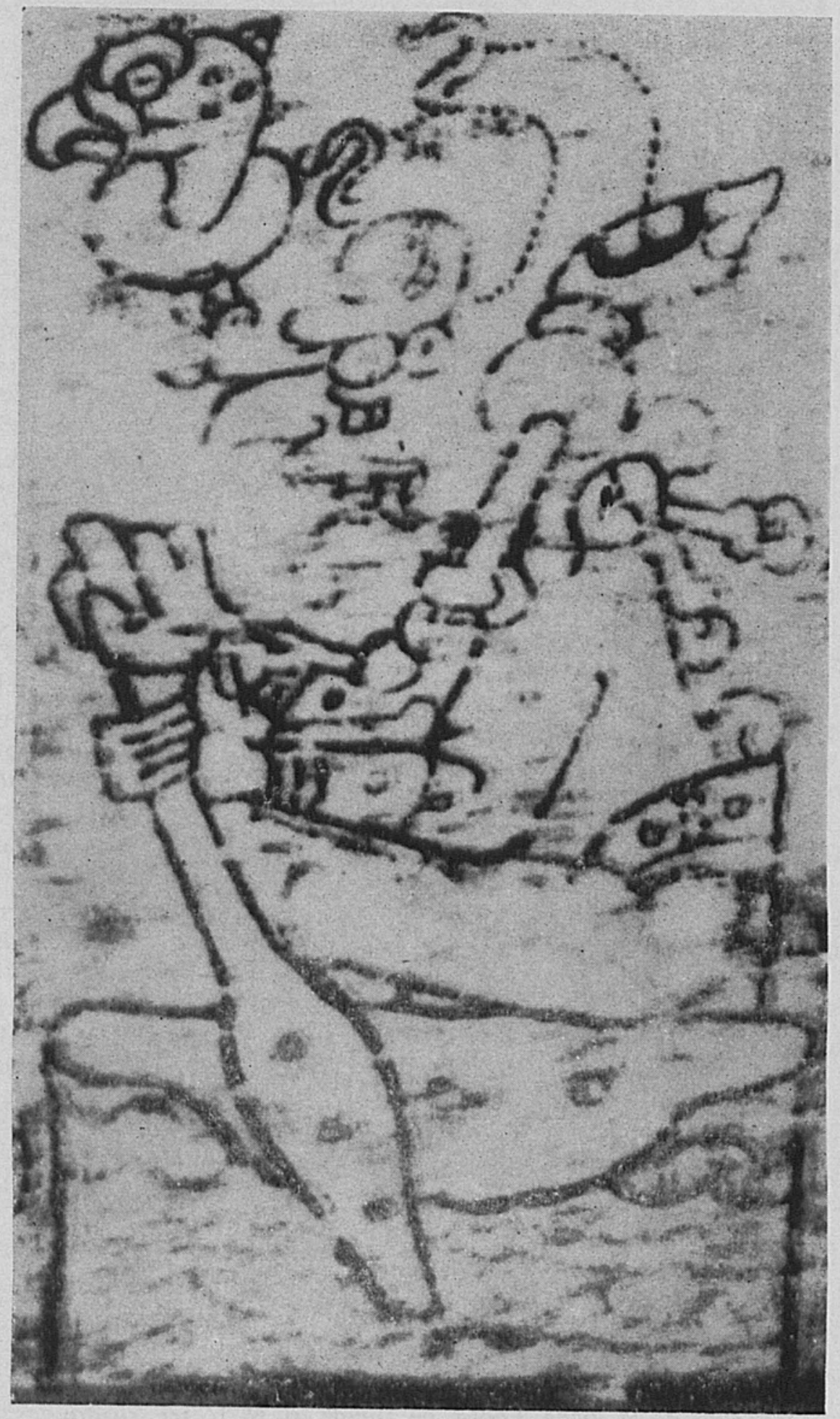

2. Dios de la lluvia. Códice de Dresde, p. 29 c-ler. cuadro. 


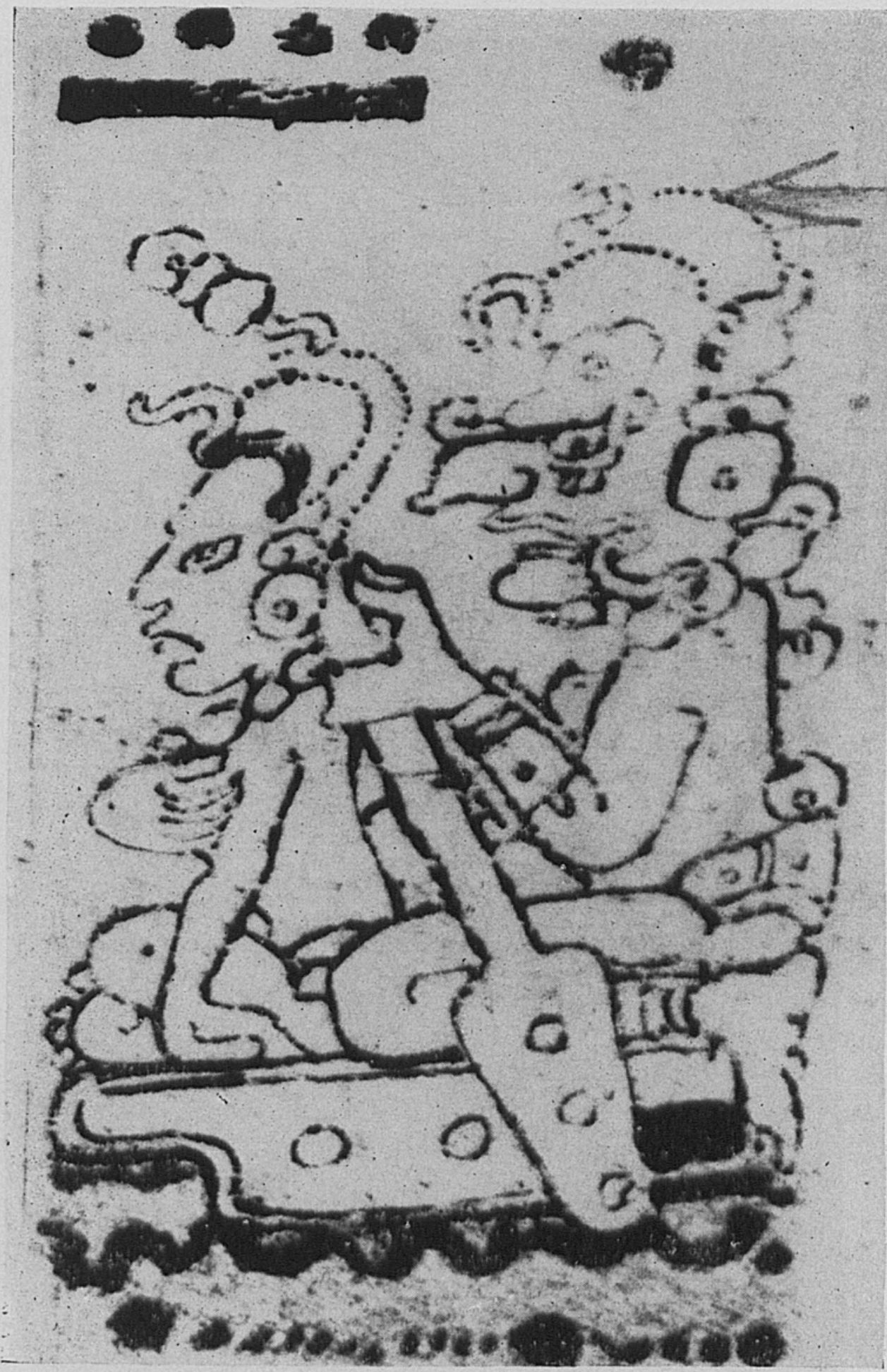

3. Dios de la lluvia y dios del maiz. Códice de Dresde, p. 36 - b $2^{\circ}$ cuadro. 


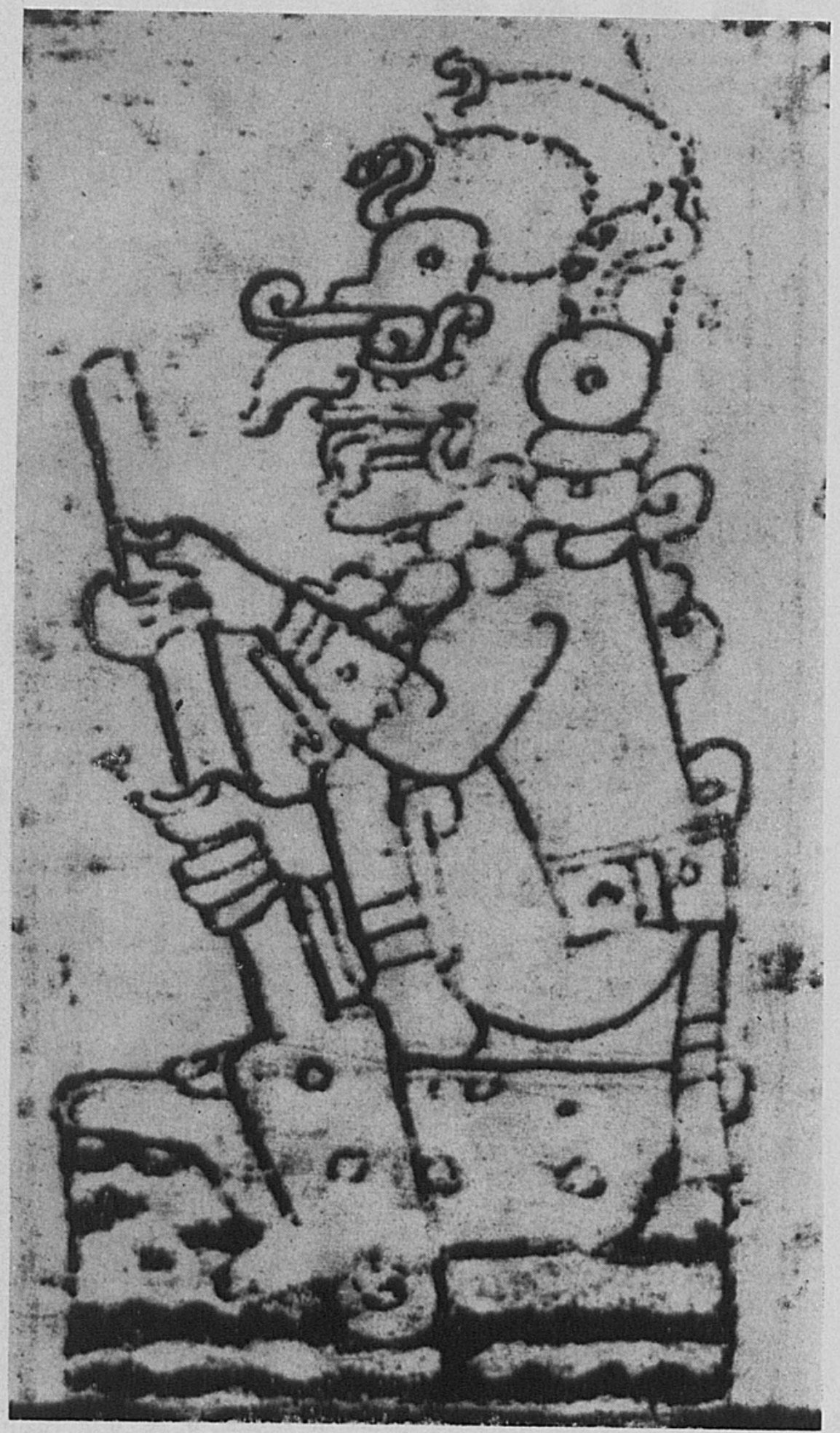

4. Dios de la lluvia. Códice de Dresde, p. 40 a-1er. cuadro. 


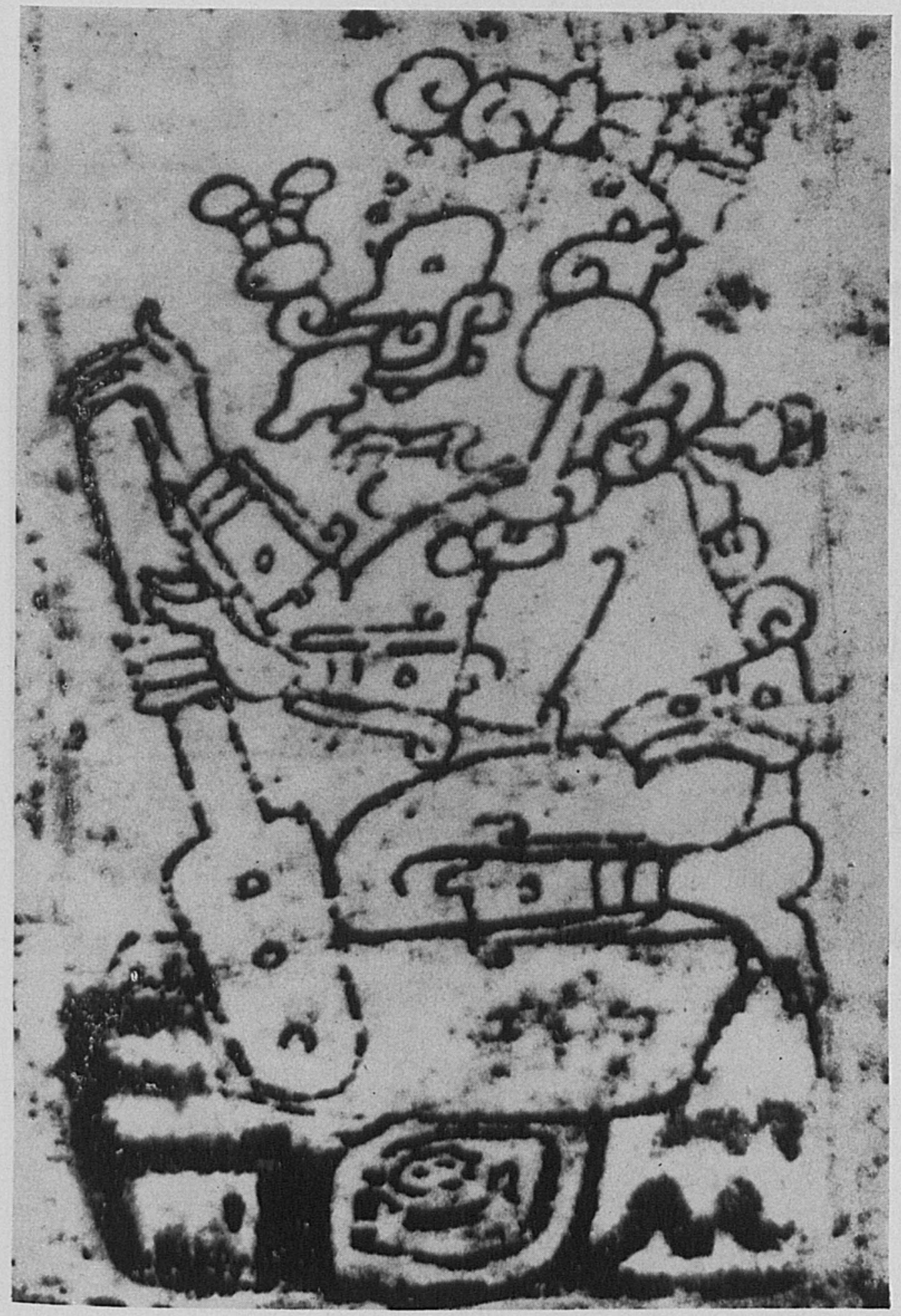

5. Dios de la lluvia. Códice de Dresde, p. 40 c-ler. cuadro. 


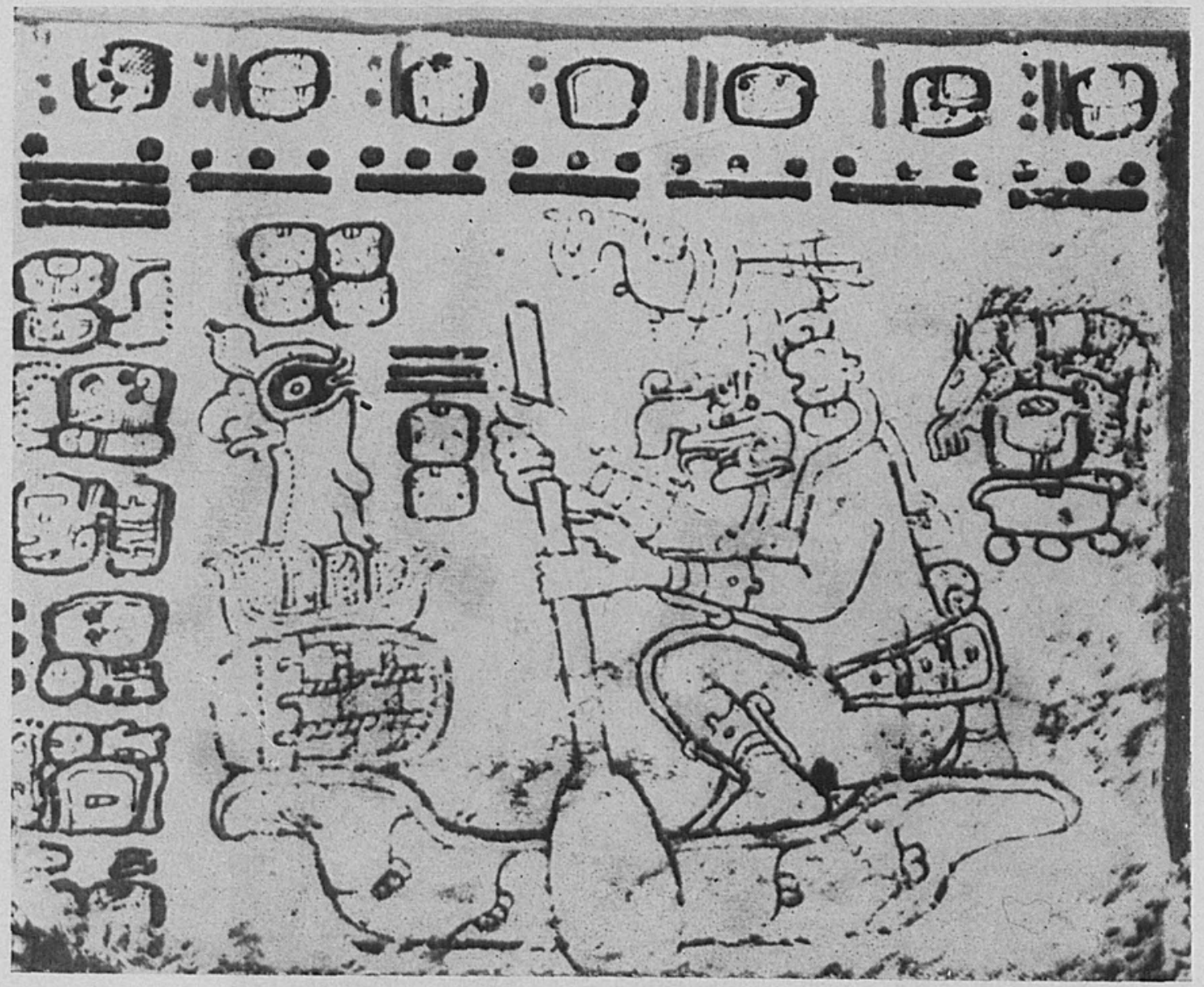

6. Dios de la lluvia. Códice de Dresde, p. 43 c. 
DOI: http://dx.doi.org/10.22201/iie.18703062e.19̉67.36.838
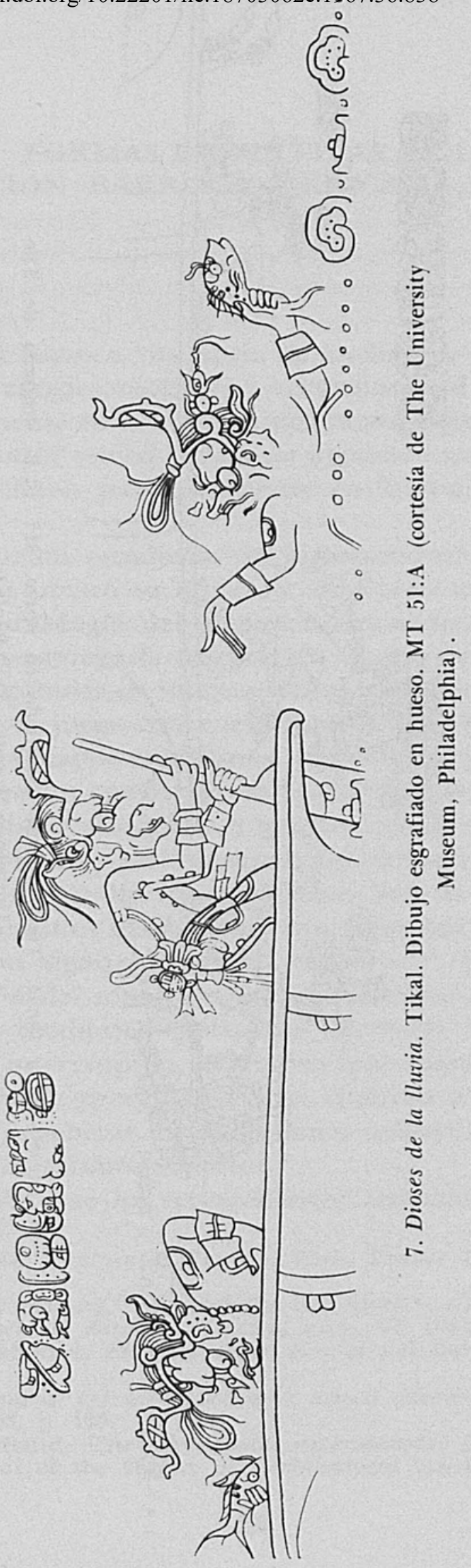
DOI: http://dx.doi.org/10.22201/iie.187030626.1967.36.838

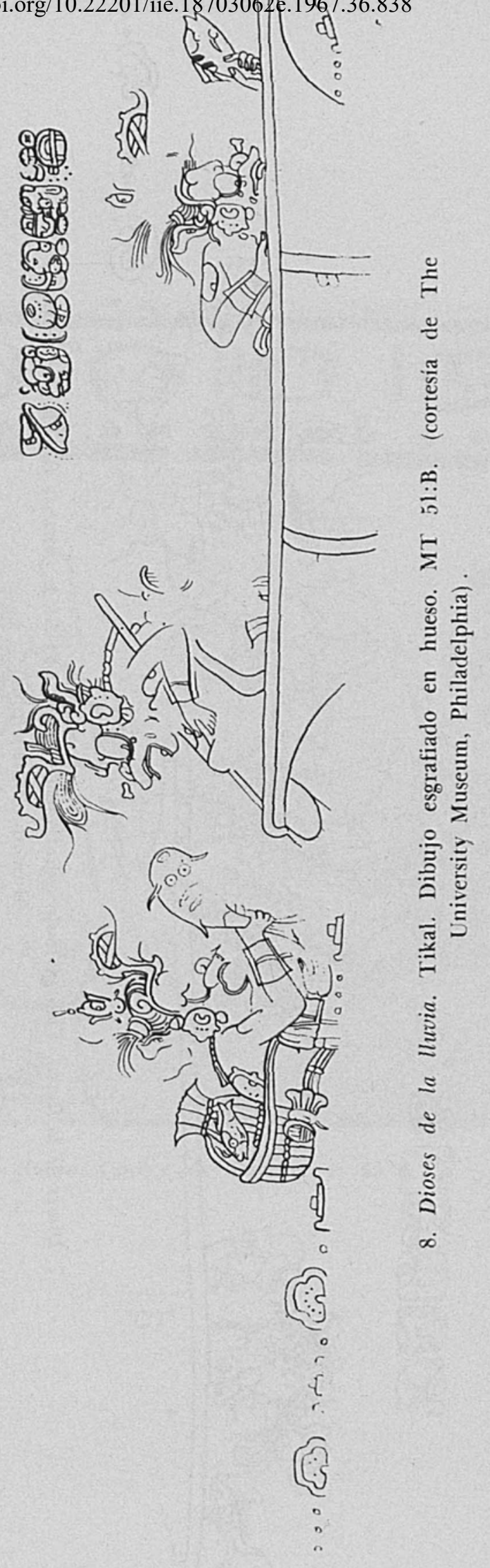

